\title{
Medical errors in neonatal intensive care unit at Benha University Hospital, Egypt
}

Ahmed N. El-Shazly', Mahmoud A. Al-Azzouny' ${ }^{2}$ Doaa R. Soliman' ', Neveen T. Abed ' and Sameh S. Attia ${ }^{\text {' }}$

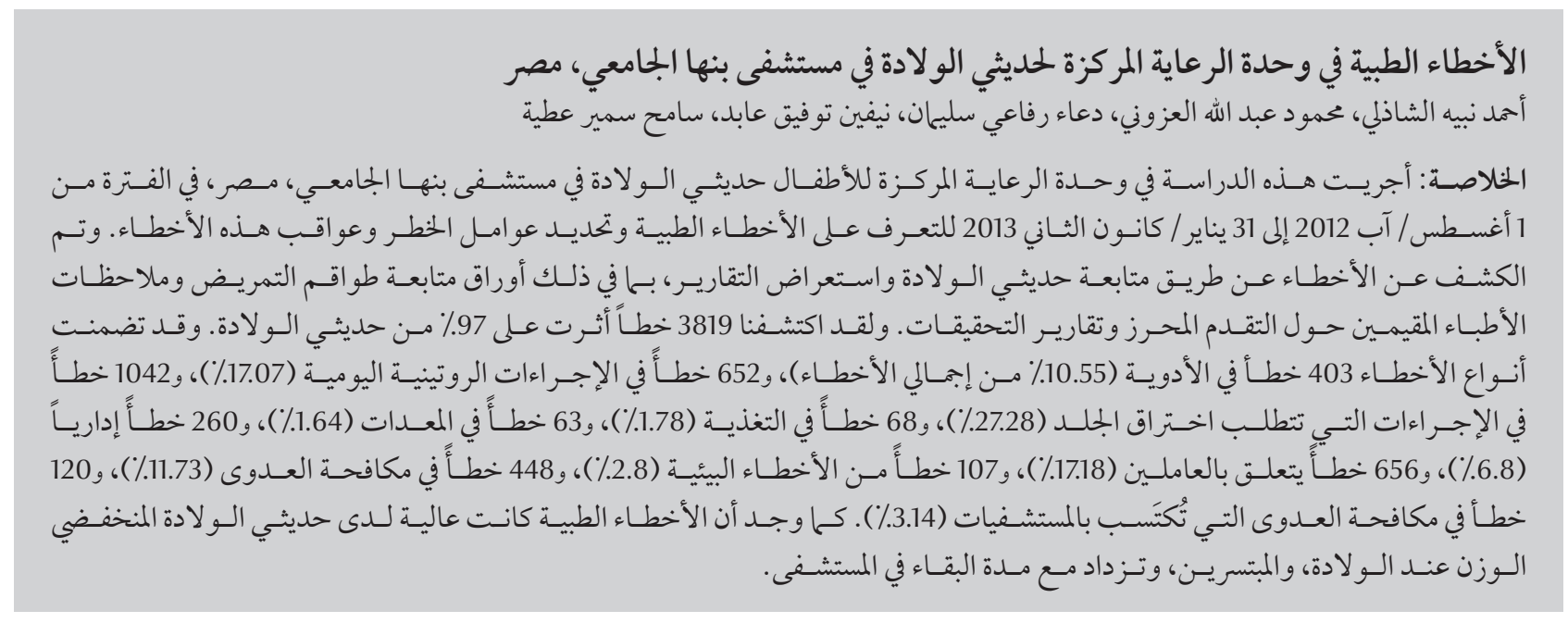

ABSTRACT This study was conducted in the neonatal intensive care unit of Benha University Hospital, Egypt from 1 August 2012 to the 31 January 2013 to identify medical errors and to determine the risk factors and consequences of these errors. Errors were detected by follow-up of neonates and review of reports including nursing followup sheets, resident progression notes and investigation reports. We detected 3819 errors that affected $97 \%$ of neonates. Types of errors included 403 medication errors (10.55\% of total errors), 652 errors in daily routine procedures (17.07\%), 1042 errors in invasive procedures (27.28\%), 68 errors in nutrition (1.78\%), 63 equipment errors (1.64\%), 260 administration errors (6.8\%), 656 staffing errors (17.18\%), 107 environmental errors (2.8\%), 448 infection control errors (11.73\%) and 120 nosocomial infection errors (3.14\%). Medical errors were high in low birth weight, low gestational age neonates and increased with duration of admission.

\section{Erreurs médicales dans l'unité néonatale de soins intensifs du centre hospitalier universitaire de Banha,} Égypte

RÉSUMÉ La présente étude a été conduite dans l'unité néonatale de soins intensifs du centre hospitalier universitaire de Banha, en Égypte, du 1 1er août 2012 au 31 janvier 2013, dans le but d'identifier les erreurs médicales et de déterminer les facteurs de risque et les conséquences associés. Des erreurs ont été détectées dans le suivi des nouveau-nés et l'analyse de rapports incluant des fiches de suivi des soins infirmiers, des notes sur la progression des internes, et des rapports d'enquête. Nous avons détecté 3819 erreurs ayant affecté $97 \%$ des nouveau-nés. Les types d'erreurs incluaient 403 erreurs de médication (10,55 \% du nombre total d'erreurs), 652 erreurs dans les actes de routine journaliers (17,07\%), 1042 erreurs dans les procédures invasives (27,28\%), 68 erreurs de nutrition (1,78\%), 63 erreurs d'équipement (1,64\%), 260 erreurs administratives (6,8\%), 656 erreurs au niveau du personnel $(17,18 \%), 107$ erreurs en matière de pratiques environnementales $(2,8 \%), 448$ erreurs liées à la lutte contre les infections (11,73 \%) et 120 erreurs entraînant des infections nosocomiales (3,14 \%). Les erreurs médicales étaient nombreuses dans les cas de nouveau-nés souffrant d'une insuffisance pondérale à la naissance ou étant nés prématurément, et elles augmentaient en fonction de la durée de l’hospitalisation.

'Department of Pediatrics, Faculty of Medicine, Benha University, Benha, Egypt (Correspondence to: S.S. Attia:dr_same72000@yahoo.com). ${ }^{2}$ Department of Clinical and Chemical Pathology, Faculty of Medicine, Benha University, Benha, Egypt.

Received: 6/7/2015; accepted: 31/8/2016 


\section{Introduction}

There is increasing interest worldwide in medical errors and their negative impact on health (1). Errors that are potentially harmful are 8 times more likely to occur in the neonatal intensive care unit (NICU) as compared with adult settings in the hospital (2). Neonates are at high risk for medication errors because of their low weight, physiological immaturity, limited compensatory abilities and extensive exposure to medication in the NICU (3). When a medical error occurs, whether it harms the patient (an adverse event) or not (a near miss), it should be investigated to determine the factors that led to its occurrence. An important part of such an investigation is analysis of the human factors that have contributed to the event. A systematic investigation should be carried out into the exact circumstances surrounding the event: lighting, environmental noise level, faulty equipment, the patients and the involved health professionals (4). Multi-institutional, voluntary, nonpunitive, error-reporting systems are likely to offer beneficial data on types, causes, results and preventability of errors in the NICU (5). This study was conducted in the NICU, Benha University Hospital, Egypt to identify medical errors and to determine the risk factors and consequences of these errors.

\section{Methods}

\section{Study design and patients}

This study had a prospective part that was done by observation of neonates from admission to discharge, and a retrospective part that involved reviewing the medical records of the same neonates. The study involved all neonates admitted to the NICU of Benha University Hospital from the 1 August 2012 to the 31 January 2013, at different times of day (morning, evening and night shifts) and weekends. The unit had a capacity of 12 incubators, 6 mechanical ventilators, 4 continuous positive airway pressure (CPAP) machines, 1 portable $\mathrm{X}$ ray apparatus and 2 resuscitators. There were no beds for phototherapy (all babies were inside incubators) and no isolation areas. Inclusion criteria: babies from birth to age 30 days and preterm and full-term neonates. Exclusion criteria: neonates with history or signs of iatrogenic complications before NICU admission and babies admitted solely for follow-up or observation for $<24$ hours (such as feeding or minimal oxygen support after delivery).

A total of 178 neonates were admitted and 30 were excluded (23 with iatrogenic complications and referred to the NICU, e.g., calcium burn, pneumothorax or perforated oesophagus, and 7 were aged $>30$ days at admission). This left a study group of 148 neonates, whose characteristics are shown in Table 1 .

\section{Data collection}

Observations were made by 1 researcher who used a sheet with a list of possible medical errors. This list was developed by reviewing the related literature and under supervision of the authors. Observations were made 5-7 times weekly in the morning shift (08:00-14:00 hours), evening shift (14:00-20:00 hours) and night shift (20:00-08:00 hours). All the admitted neonates were subjected to the following: (1) complete history, including postnatal age, sex, gestational age, mode of delivery, cause of admission, history of admission to other NICUs, or history of any procedures such as endotracheal intubation, chest tube or umbilical catheterization; (2) thorough clinical examination for identification of any suggestive signs of iatrogenic origin, for example, ulcer, gangrene, burn or extravasation; (3) follow-up for all cases during NICU stay to detect medical errors and iatrogenic complications induced by therapeutic or diagnostic procedures; and (4) monitoring through reviewing of daily morning reports, nursing follow-up sheets, resident progression notes, radiographs and laboratory investigations (reviewing was done after baby discharge or death).

\section{Errors}

Errors included medication errors, errors in daily routine procedures, errors

\begin{tabular}{|c|c|c|}
\hline \multicolumn{3}{|l|}{ Table 1 Patient characteristics } \\
\hline & $\mathrm{n}=148$ & $\%$ \\
\hline \multicolumn{3}{|l|}{ Gender } \\
\hline Male & 75 & 50.7 \\
\hline Female & 73 & 49.3 \\
\hline \multicolumn{3}{|l|}{ Gestational age (wk) } \\
\hline Preterm $<37$ & 86 & 58.1 \\
\hline Full term $\geq 37$ & 62 & 41.9 \\
\hline Gestational age, mean (SD), range & 35.09 (3.73), 26-41 wks & \\
\hline Admission weight, mean (SD), range (kg) & $2.43(0.9), 0.8-4.5 \mathrm{~kg}$ & \\
\hline \multicolumn{3}{|l|}{ Gestation type } \\
\hline Single baby & 131 & 88.5 \\
\hline One of twins & 10 & 6.8 \\
\hline One of triplets & 7 & 4.7 \\
\hline \multicolumn{3}{|l|}{ Mode of delivery } \\
\hline Normal vaginal delivery & 59 & 39.9 \\
\hline Caesarean section & 89 & 60.1 \\
\hline Duration of admission, mean (SD), range & $12.59(3.55), 1-140 \mathrm{~d}$ & \\
\hline Age at admission, mean (SD), range & $4.35(5.74), 1-30 \mathrm{~d}$ & \\
\hline
\end{tabular}

$S D=$ standard deviation . 
in invasive procedures, errors in nutrition, equipment errors, administration errors, staffing errors, environmental errors, infection control errors and nosocomial infection errors. This classification of errors was made after a search of PubMed using the following terms: medical errors, adverse events, iatrogenic complications and hazards in neonatal intensive care unit. Medical errors were defined as any error in the delivery of medical care, regardless of whether it had the potential to cause harm or not (1). Medical errors were categorized using a modification of Leape's classification of medical errors (6) and NICQ 2007: Improvement in Action (7), as well as several other schemes described in the literature (8-12).

Subcategories of medication errors were as described by Kaushal et al. (2). The standards for drug dose, drug administration and invasive procedures were based on Cloherty's Manual of Neonatal Care 5th edition (13).

Severity of errors was graded according to the classification of the National Coordinating Council for Medication Error Reporting and Prevention (14). Each category of errors had a degree of severity as follows:

A: incidents that had the capability to cause errors;

B: an error happened but it did not reach the patient;

C: an error happened but did not harm the patient;

D: an error happened that needed monitoring and/or required intervention to prevent harm;

E: an error happened that resulted in temporary harm to the patient and required intervention;

F: an error happened that resulted in temporary harm to the patient and extension of stay in the NICU;

G: an error happened and resulted in permanent patient harm;

$\mathrm{H}$ : an error happened and needed intervention to sustain life;
I: an error happened that may have contributed to or resulted in patient death.

\section{Ethical considerations}

The entire medical and nursing staff of the NICU were notified about the study. Reports of medical errors were anonymous and we emphasized that reporting would not be used to apportion blame to any individual but to aid error detection with a view to system improvement. We directed medical personnel during information sessions about medical errors and how to avoid repeating these errors. The Ethics Committee of the hospital approved the study.

\section{Statistical analysis}

The variables analysed in our study were types of error, distribution of errors, admission weight, gestational age, age at admission, duration of admission, mode of delivery, presentation at admission and invasive procedures. We also analysed other variables that may have been related to risk factors for errors, such as experience of resident (senior was $>1$ year and junior $<1$ year experience), working days and holidays, and shifts. All data were revised for completeness and consistency. Precoded data were entered into the computer using Excel for Windows (2010). The data were summarized in terms of numbers and percentages for qualitative data, and mean (standard deviation; SD) and range for quantitative data. Comparisons between the different groups of the study sample were carried out using the Mann-Whitney test to compare 2 groups and Kruskal-Wallis test to compare $\geq 3$ groups. Correlations between medical errors detected and some characteristics of the study group were assessed using the Spearman correlation coefficient $(\rho) . P<0.05$ was considered statistically significant and $P<0.001$ was considered highly significant. The statistical analysis was conducted using SPSS version 19.

\section{Results}

Eighty-nine (60.2\%) neonates were admitted to the NICU with respiratory distress, 24 (16.2\%) with neonatal jaundice, 10 (6.8\%) with lethargy, 7 (4.7\%) with type 1 diabetes, 5 (3.4\%) with intrauterine growth retardation (small for date), 4 (2.7\%) with convulsion, 3 (2.0\%) with coma (intracranial haemorrhage/hypoxic-ischaemic encephalopathy), 2 (1.4\%) with birth trauma (skull/arm fracture), and 1 (.07\%) each with bleeding tendency, choanal atresia, infected epiderma bullosa and multiple swelling in the body.

The invasive procedures carried out in the NICU are listed in Table 2. Peripheral venous catheterization was the most common procedure, in 256 (78.3\%) neonates, followed by endotracheal intubation in 133 (39.8\%). Venous cutdown and intraosseous needle insertion were the least common, with 1 (0.67\%) patient each.

One hundred and forty-eight neonates were followed up in the NICU for 6 months, and 3819 medical errors were detected that affected $97 \%$ of the study population (Table 3). We found that the mean number of errors per patient was 25.8 (5.08), range 0-213. There were 403 medication errors, which comprised $10.55 \%$ of the total, $652(17.07 \%)$ daily routine procedure errors, 1042 (27.28\%) invasive procedure errors, 68 (1.78\%) nutrition errors, 63 (1.64\%) equipment errors, 260 (6.8\%) administration errors, 656 (17.18\%) staffing errors, 107 (2.8\%) environmental errors, 120 (3.14\%) nosocomial infection errors and 448 (11.73\%) infection control errors.

Medication errors are described in more detail in Table 4. Dispensing errors were the most common (167, $41.43 \%$ ), followed by administration errors $(124,30.76 \%)$, prescription errors $(81,20.1 \%)$ and ordering errors $(31,7.7 \%)$. 


\begin{tabular}{lcrc}
\hline Table 2 Invasive procedures performed on neonates & & & \\
\hline Invasive procedures & No. of procedures & $\begin{array}{c}\text { No. of affected } \\
\text { neonates }\end{array}$ & \% of neonates \\
Peripheral venous catheter & 256 & 116 & 78.3 \\
Endotracheal intubation & 133 & 59 & 39.8 \\
Mechanical ventilation & 59 & 59 & 39.8 \\
Continuous positive airway pressure & 67 & 46 & 31 \\
Ambulatory ventilation & 91 & 55 & 37.1 \\
Venous cutdown & 1 & 1 & 0.67 \\
Intraosseous needle & 1 & 1 & 0.67 \\
Surgically placed central venous catheter & 35 & 35 & 23.6 \\
Umbilical venous catheter & 40 & 40 & 27 \\
Exchange transfusion & 7 & 7 & 4.7 \\
Chest tube & 10 & 9 & 6.7 \\
Blood and blood product transfusion & 118 & 54 & 12.1 \\
Urinary catheter & 18 & 18 & \\
\hline
\end{tabular}

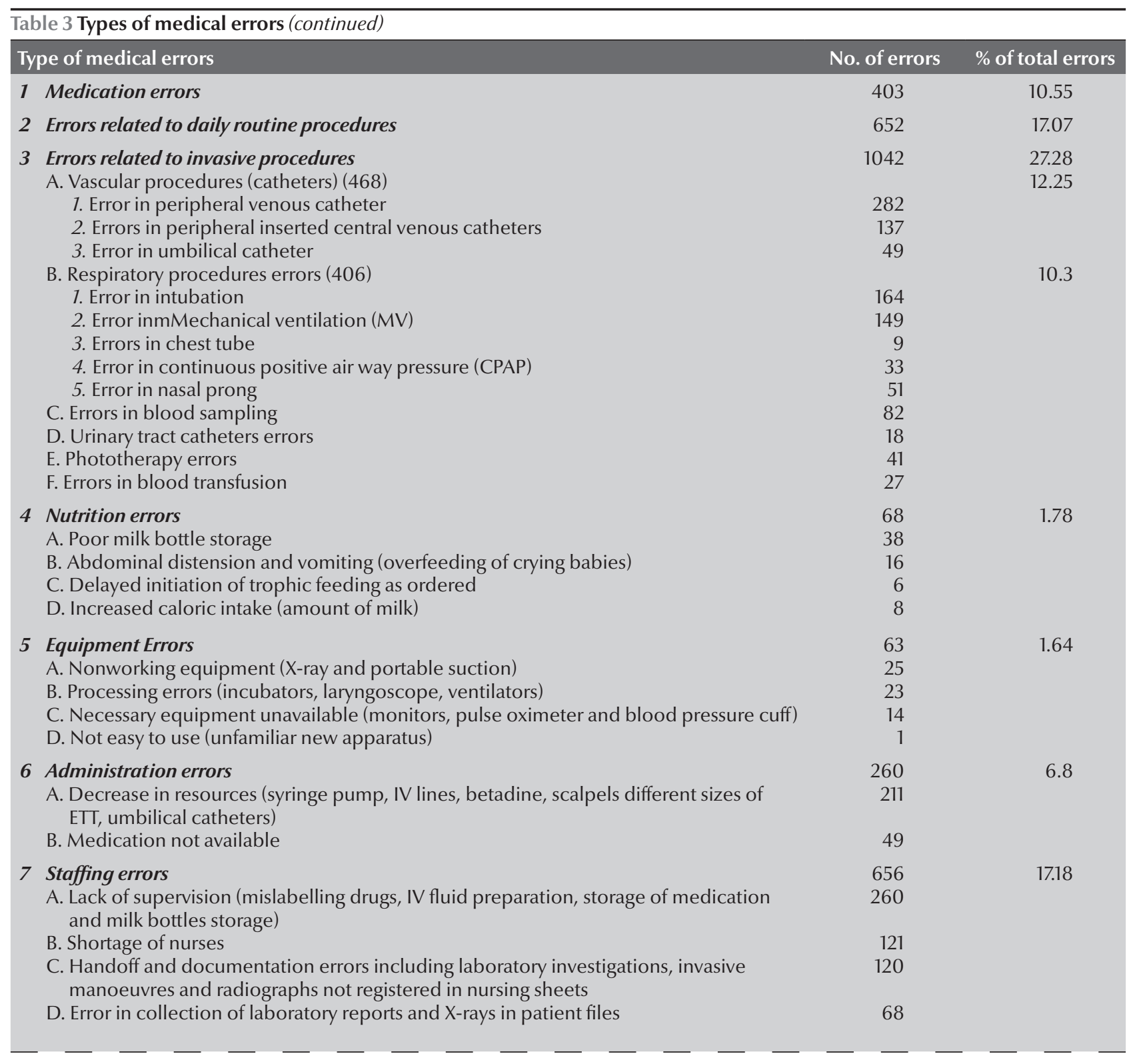




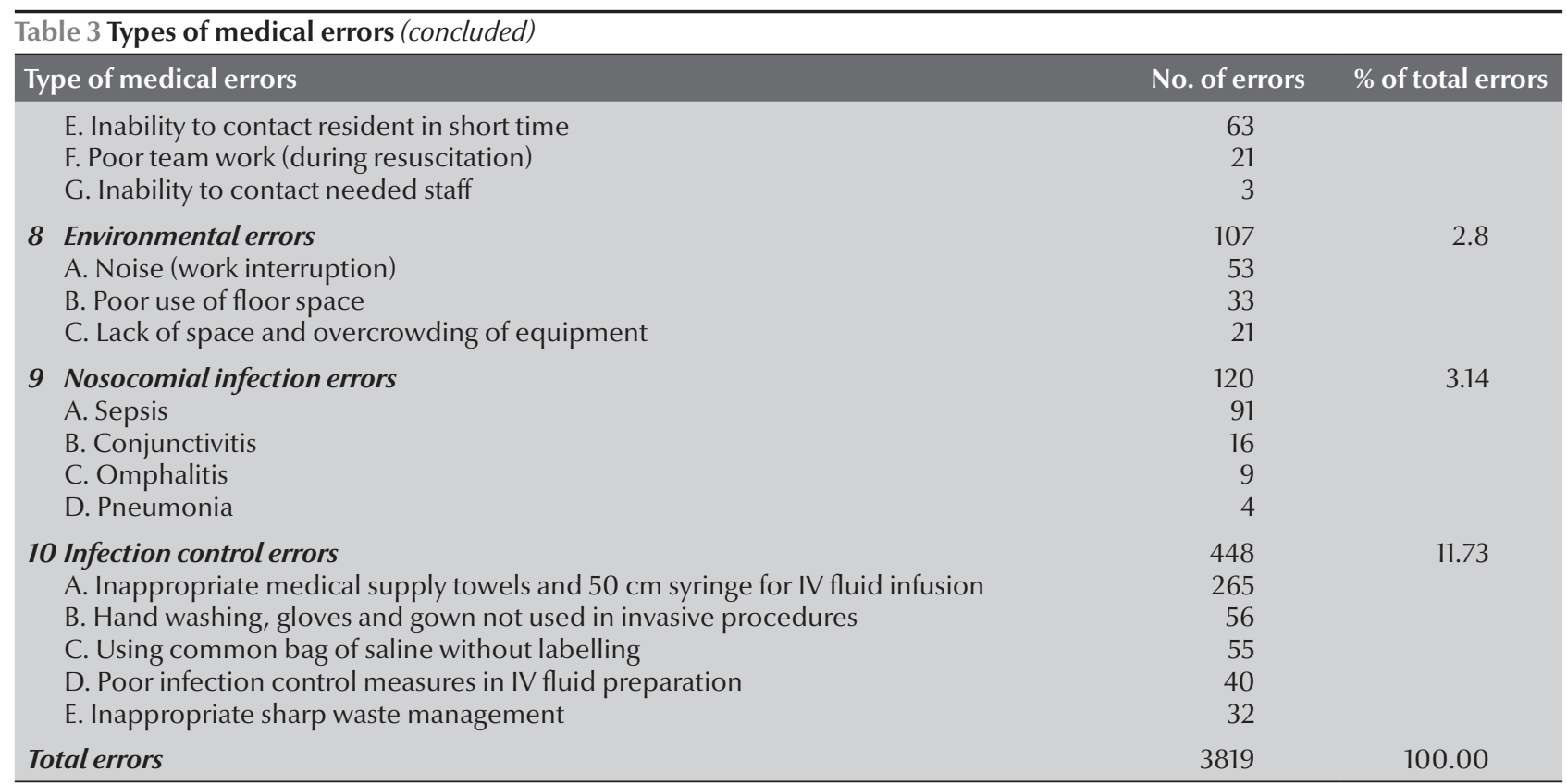

$E T T=$ endotracheal tube; $I V=$ intravenous.

\begin{tabular}{|lcr|}
\hline Table 4 Distribution of medication errors & & \\
\hline Type of medication errors & $\mathbf{n = 4 0 3}$ & $\%$ \\
\hline A. Errors in ordering & 31 & 7.7 \\
B. Errors in prescription & 81 & 20.1 \\
7. Calculation & 45 & 11.2 \\
2. Illegible prescription & 36 & 8.9 \\
C. Errors in dispensing & 167 & 41.43 \\
7. Labelling errors & 96 & 23.8 \\
2. Poor drug storage & 71 & 17.6 \\
D. Errors in administration & 124 & 30.76 \\
7. Wrong time & 63 & 15.6 \\
2. Incorrect speed of IV fluid & 30 & 7.4 \\
3. Written communication error & 17 & 4.2 \\
4. Solution set used instead of syringe pump & 9 & 2.2 \\
5. Local skin injury or chemical burn & 5 & 1.2 \\
\hline
\end{tabular}

$I V=$ intravenous.

We analysed the correlations between patients' risk factors and different types of errors. Medical errors showed a significant positive correlation with duration of admission (Figure 1A) and a significant negative correlation with weight at admission (Figure 1B) and gestational age. The maximum length of stay in the NICU was 140 days and the maximum number of errors was 213 , which appeared as extreme outliers. This neonate had congenital heart disease and was waiting for surgical correction and exposed to multiple iatrogenic complications.
There were no significant differences in errors between different shifts, except for a significant increase in administration errors in the evening and night shifts compared with the morning shift (Figure 1C). Also, we found a highly significant increase in staffing and environmental errors in the evening and night shifts compared with the morning shift (Figure 1D). There was no significant difference in errors between holidays and working days, but there was a significant increase in errors in junior residents compared with senior residents (data not shown).
Severity of errors was graded according to the classification of the National Coordinating Council for Medication Error Reporting and Prevention (14). The number ( $\%$ of total) of errors in each group was as follow: A, 1296 (33.94\%); B, 36 (0.94\%); C, 442 (11.57\%); D, 486 (12.73\%); E, 1465 (38.36\%); F, 78 (2.04\%); G, 0; H, 16 (0.42\%) and I, 0.

\section{Discussion}

In this study, we reported different types of medical errors that affected $97 \%$ of neonates, which is considered a high percentage, which agreed with a study in an NICU in the United States of America where medication errors occurred in $91 \%$ of admitted cases (2). In a study in India, medical errors were detected in $76.6 \%$ of neonates admitted to the NICU (15). Our number of errors was considerably higher than that in a prospective observational interventional study performed in 4 tertiary, university-affiliated NICUs in Israel, where the prevalence rate of iatrogenic events was only $18.8 \%$ of hospitalized infants (16). So, there is wide variation between our results and others and this 


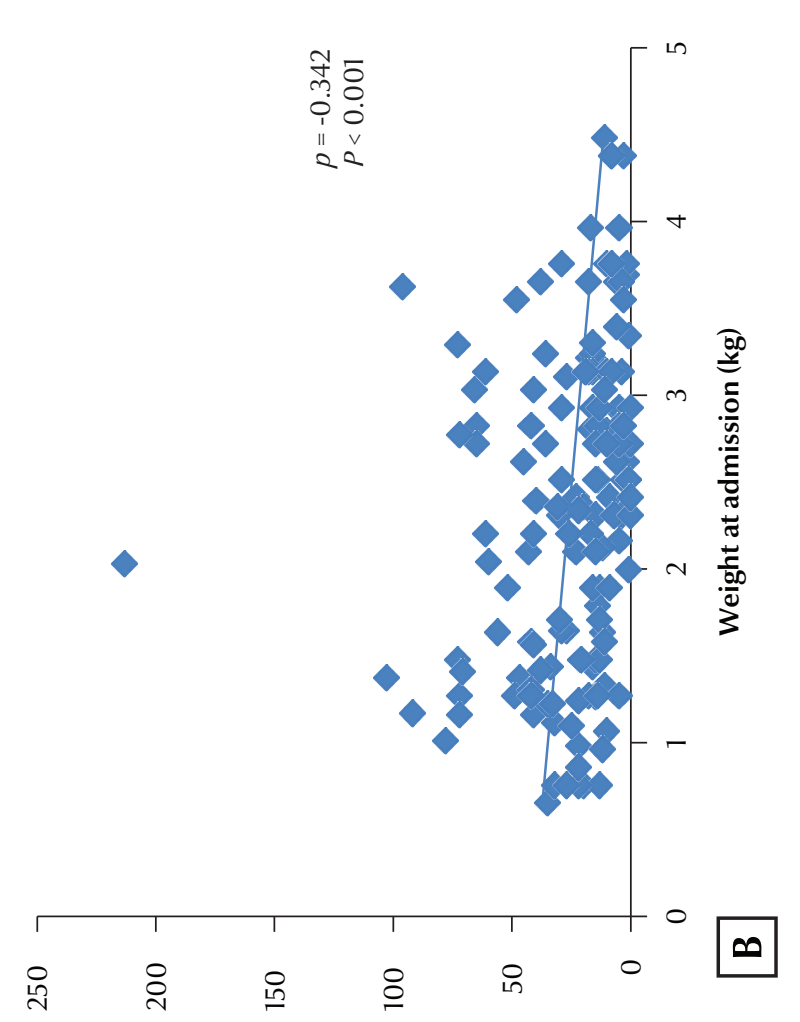

S.омว ןеро।

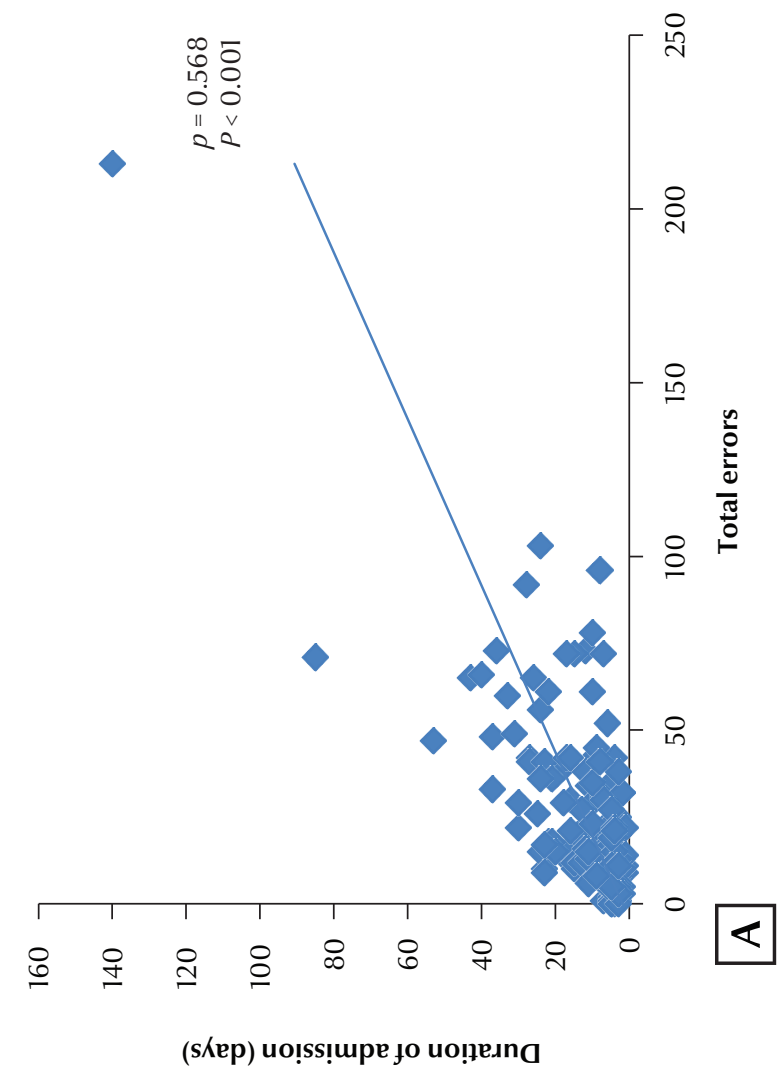

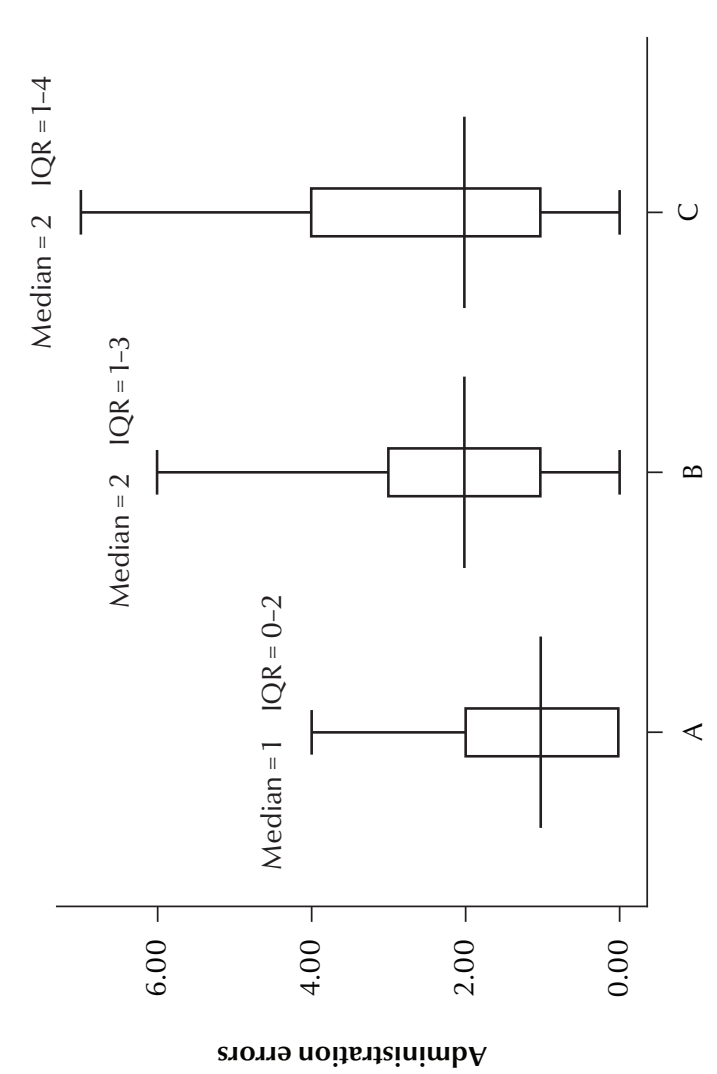

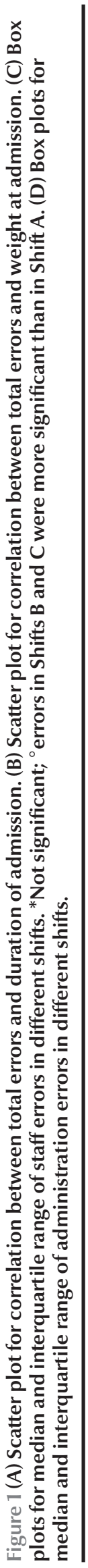


may have resulted from differences in the classification of errors and the methods used to identify them.

The high rate of medical errors detected in our study may have been because it was conducted in a developing country where there is under-financing of essential health services, poor infrastructure and poor performance of personnel because of low motivation and insufficient technical skills. All these factors make the probability of medical errors higher than in developed countries. Another explanation for our high rate of medical errors is the use of two methods for error detection, the followup method and the method of review of medical records.

Errors in invasive procedures were the most frequent type, comprising $27.28 \%$ of the total number of medical errors. Within that group, catheterization errors (peripheral venous, peripheral inserted central venous and umbilical catheters) were the most common type of error, constituting $12.2 \%$ of the total number of medical errors. This was followed by respiratory procedure errors (intubation, mechanical ventilation, CPAP and nasal Prong), which comprised $10.3 \%$ of the total number of medical errors. These results are consistent with a study in which catheter errors were the most common iatrogenic events (20\% of total), followed by respiratory procedure errors (16\%) (16). Another study reported that cutaneous injuries (peripheral catheter-related lesions) were the most common iatrogenic event (10). Thus, it is clear that high numbers of errors in invasive procedures result mainly from catheter and respiratory procedure errors.

In our study, medication errors were low and represented $10.55 \%$ of total errors. This agrees with a previous report that medication errors comprised 13\% of total iatrogenic events (16), whereas other studies have reported that medication errors represented $68.5 \%$ of total errors (15). Another study found that half of the iatrogenic complications in the NICU were related to medication errors (9). Thus, we found wide variation between our own and other results. Such variation was confirmed by Chedoe et al., who suggested that the differences were due to variation in the definition of errors and the accuracy of the method used to identify them (17). Also, it is reported that studies of errors in the NICU are rare and most focus on medication errors (5).

With regard to nosocomial infection, neonatal sepsis affected 91 neonates $(61.4 \%)$ in our study, which agrees with a study in Southern Brazil that reported a $45.8 \%$ incidence of nosocomial infection in neonates (18). Garland and Uhing have reported that hospital-acquired infections, which can result from medical procedure errors, continue to be common in the NICU, often resulting in significant morbidity, mortality and increased length of stay (19). However, this disagrees with other studies that have reported that nosocomial infection represented only $15 \%$ of iatrogenic events (16) and an incidence of up to $20 \%$ in the NICU (20). The high rate of nosocomial infection in our study can be explained by the fact that most comparable studies were conducted in more developed countries. This agrees with a study in which rates of neonatal infection were 3-20 times higher in developing countries than in developed countries (21).

To identify risk factors associated with the development of medical errors, we explored the role of factors related to patients as well as staffing, administration, equipment, environment and infection control practices. Considering the patient factors, there was a significant inverse correlation between gestational age, birth weight and different types of medical errors, which agrees with many studies that found a significant inverse correlation between birth weight and medical errors (3). It is also reported that higher rates of adverse events occurred in infants with low gestational age $(16,22)$.

There was a significant positive correlation between medical errors and duration of admission, which was not unexpected because extremely premature infants are prone to various diseases during long hospital stays and exposed to more invasive procedures. This is consistent with studies in which neonates with low birth weight had longer length of stay and required complex invasive manoeuvres, so they had more frequent medical errors $(10,16)$.

We found that staffing errors represented $17.18 \%$ of the total errors and lack of supervision, shortage of nurses and poor communication between residents and nurses were important risk factors. The number of medical errors was increased by work overload and fatigue. This agrees with a study in which a decrease in the number of nurses correlated with an increase in human errors and led to adverse events (23). It has also been shown that poor communication among healthcare providers leads to poor teamwork and potentially increases unsafe practices (24).

We found that administration errors accounted for $6.8 \%$ of total errors. There was a lack of some medications due to unavailability in the hospital pharmacy. Also, there were deficiencies in some medical supplies, such as blood sugar strips, and different sizes of endotracheal tubes, umbilical catheters, suction tubes and scalpels. These factors had a negative impact on the performance of the healthcare system and health outcomes. This agrees with a study in 4 hospitals in Southeast Asia where cost of neonatal care, hospital infrastructure and access to medication are important barriers to neonatal care in developing countries (25).

Equipment errors represented $1.64 \%$ of total errors in our study and we reported defects in essential equipment such as monitors, pulse oximeters, X-ray apparatus, portable suction equipment, 
and monitors. This agrees with other studies that reported that failure in medical devices was one of the causes of near misses in the NICU $(26,27)$.

Environmental errors comprised $2.8 \%$ of total errors in our study. We found that poor use of floor space, noise and lack of space were common environmental problems, which may be attributed to overcrowding by staff and lack of organization, especially in morning shifts. Similarly, Brown reported that premature infants in the NICU are often exposed to continuous loud noise (28). Therefore, it is recommended that reducing noise in the NICU should be a top priority because medically fragile, vulnerable preterm infants need a more developmentally friendly auditory environment. NICU caregivers, especially nurses can do much to create a friendly and less noisy environment (29).

We found a significant increase in medical errors in junior residents compared with senior residents, which may have been due to lack of training and experience in the former. This agrees with a study that found an increase in errors when new doctors joined the rotation or when there was change to junior medical staff (30).

With regard to the severity of medicalerrors, ourstudyrevealed that Groups A-D were minor errors (59.18\%) and included the majority of errors. Group E errors (38.36\%) resulted in temporary harm to the patients and required intervention. Group F errors (2.04\%) resulted in temporary harm to the patient and required initial or prolonged hospitalization. These latter 2 groups were moderate errors. Group H errors $(0.42 \%)$ required life-saving intervention and were considered severe errors. In our study, minor errors were the most common, followed by moderate and severe errors. This agrees with a study that reported $61 \%$ minor errors, $26 \%$ moderate errors and $13 \%$ major errors (11). However, our results disagree with another study that reported 30\% major errors (death or need for ICUspecific intervention), 25\% moderate errors (requiring routine therapy available outside the ICU) and $45 \%$ minor errors (no intervention required) (27).

There were some limitations to our study. First, it was conducted in 1 hospital, in which, the medical errors may have differed from those in other hospitals. Thus, further research is needed, including university and Ministry of Health hospitals, to detect and report different types of errors. Second, classification of errors was made by only 1 reviewer, so it was not possible to determine the reliability of this reviewer.

\section{Conclusion}

Medical errors were high in low birth weight, low gestational age neonates and increased with longer NICU stay. Most errors resulted in minor problems but some were serious and needed intervention or extended hospitalization.

Funding: None.

Competing interests: None declared.

\section{References}

1. Landrigan CP. The safety of inpatient pediatrics: preventing medical errors and injuries among hospitalized children. Pediatr Clin North Am. 2005 Aug;52(4):979-93, vii. PMID:16009253

2. Kaushal R, Bates DW, Landrigan C, McKenna KJ, Clapp MD, Federico $F$, et al. Medication errors and adverse drug events in pediatric inpatients. JAMA. 2001 Apr 25;285(16):2114-20. PMID:11311101

3. Kanter DE, Turenne W, Slonim AD. Hospital-reported medical errors in premature neonates. Pediatr Crit Care Med. 2004 Mar;5(2):119-23. PMID:14987340

4. Handyside J, Suresh G. Human factors and quality improvement. Clin Perinatol. 2010 Mar;37(1):123-40. PMID:20363451

5. Snijders C, van Lingen RA, Molendijk A, Fetter WPF. Incident and errors in neonatal intensive care: a review of the literature. Arch Dis Child Fetal Neonatal Ed. 2007 Sep;92:F391-8. PMID:17376782

6. Leape LL, Lawthers AG, Brennan TA, Johnson WG. Preventing medical injury. QRB Qual Rev Bull. 1993 May;19(5):144-9. PMID:8332330

7. Handyside J. System safety in the NICU. In: Horbar JD, Leahy K, Handyside J, editors. NICQ 2007: improvement in action. Burlington: Vermont Oxford Network; 2010:2-1-2-14 (https://public.vtoxford.org/wp-content/uploads/2014/04/ NICQ_2007_ebook.pdf, accessed 19 October 2016).

8. Suresh G, Horbar JD, Plsek P, Gray J, Edwards WH, Shiono PH, et al. Voluntary anonymous reporting of medical errors for neonatal intensive care. Pediatrics. 2004 Jun;113(6):1609-18. PMID:15173481

9. Sekar KC. latrogenic complications in the neonatal intensive care unit. J Perinatol. 2010 Oct;30 Suppl:S51-6. PMID:20877408

10. Ligi I, Arnaud F, Jouve E, Tardieu S, Sambuc R, Simeoni U. latrogenic events in admitted neonates: a prospective cohort study. Lancet. 2008 Feb 2;371(9610):404-10. PMID:18242414

11. Niesse OW, Sennhauser FH, Frey B. Critical incidents in paediatric critical care: who is at risk? Eur J Pediatr. 2011 Feb;170(2):193-8. PMID:20827559

12. Snijders C, van Lingen RA, van der Schaaf TW, Fetter WPF, Molendijk HA; NEOSAFE study group. Incidents associated with mechanical ventilation and intravascular catheters in neonatal intensive care: exploration of the causes, severity and methods for prevention. Arch Dis Child Fetal Neonatal Ed. 2011 Mar;96(2):F121-6. PMID:20870905

13. ClohertyJP, Eichenwald EC, Stark AR. Cloherty's manual of neonatal care. 5th edition. Philadelphia: Lippincott Williams and Williams; 2004.

14. National Coordinating Council for Medication Error Reporting and Prevention. (http://www.nccmerp.org, Accessed 19 October 2016).

15. Parihar M and Passi G R. Medical errors in pediatric practice. Indian Pediatr. 2008 Jul;45(7):586-9. PMID:18695280

16. Kugelman A, Inbar-Sanado E, Shinwell ES, Makhoul IR, Leshem $M$, Zangen $S$, et al. latrogenesis in neonatal intensive care units: 
observational and interventional, prospective, multicenter study. Pediatrics. 2008 Sep;122(3):550-5. PMID:18762525

17. Chedoe I, Molendijk HA, Dittrich ST, Jansman FG, Harting JW, Brouwers JR, et al. Incidence and nature of medication errors in neonatal intensive care with strategies to improve safety: a review of the current literature. Drug Saf. 2007;30(6):503-13. PMID:17536876

18. Dal-Bó K, da Silva RM, Sakae TM. Infecção hospitalar em uma unidade de terapia intensiva neonatal do Sul do Brasil [Nosocomial infections in a neonatal intensive care unit in South Brazil] Rev Bras Ter Intensiva. 2012 Oct/Dec;24(4):381-5 (in Portuguese) (http://www.scielo.br/scielo.php?pid=S0103507X2012000400015\&script=sci_arttext\&tlng=en).

19. Garland JS, Uhing MR. Strategies to prevent bacterial and fungal infection in the neonatal intensive care unit. Clin Perinatol. 2009 Mar;36(1):1-13. PMID:19161861

20. Banerjee SN, Grohskopf LA, Sinkowitz-Cochran RL, Jarvis WR National Nosocomial Infections Surveillance System; Pediatric Prevention Network. Incidence of pediatric and neonatal intensive care unit-acquired infections. Infect Control Hosp Epidemiol. 2006 Jun;27(6):561-70. PMID:16755474

21. Zaidi AK, Huskins WC, Thaver D, Bhutta ZA, Abbas Z, Goldmann DA. Hospital-acquired neonatal infections in developing countries. Lancet. 2005 Mar 26;365(9465):1175-88. PMID:15794973

22. Sharek PJ, Horbar JD, Mason W, Bisarya H, Thurm CW, Suresh $\mathrm{G}$, et al. Adverse events in the neonatal intensive care unit: development, testing, and findings of an NICU-focused trigger tool to identify harm in North American NICUs. Pediatrics. 2006 Oct;118(4):1332-40. PMID:17015521
23. Lamy Filho F, Silva AA, Lopes JM, Lamy ZC, Simões VM, Dos Santos AM. Staff workload and adverse events during mechanical ventilation in neonatal intensive care units. J Pediatr (Rio J). 2011 Nov-Dec;87(6):487-92. PMID:22068699

24. Jirapaet V, Jirapaet K, Sopajaree C. The nurses' experience of barriers to safe practice in the neonatal intensive care unit in Thailand. J Obstet Gynecol Neonatal Nurs. 2006 NovDec;35(6):746-54. PMID:17105639

25. Martinez AM, Khu DT, Boo NY, Neou L, Saysanasongkham B, Partridge JC. Barriers to neonatal care in developing countries: parents' and providers' perceptions. J Paediatr Child Health. 2012 Sep;48(9):852-8. PMID:22970681

26. Tourgeman-Bashkin O, Shinar D, Zmora E. Causes of near misses in critical care of neonates and children. Acta Paediatr. 2008 Mar;97(3):299-303. PMID:18298777

27. Frey B, Kehrer B, Losa M, Braun H, Berweger L, Micallef J, et al. Comprehensive critical incident monitoring in a neonatal-pediatric intensive care unit: experience with the system approach. Intensive Care Med. 2000 Jan;26(1):69-74. PMID:10663283

28. Brown G. NICU noise and the preterm infant. Neonatal Netw. 2009 May-Jun;28(3):165-73. PMID:19451078

29. Levy GD, Woolston DJ, Browne JV. Mean noise amounts in level II vs level III neonatal intensive care units. Neonatal Netw. 2003 Mar-Apr;22(2):33-8. PMID:12696724

30. Simpson JH, Lynch R, Grant J, Alroomi L. Reducing medication errors in the neonatal intensive care unit. Arch Dis Child Fetal Neonatal Ed. 2004 Nov;89(6):F480-2. PMID:15499135 